\title{
The Recovery of Forelimb-Placing Behavior in Rats with Neonatal Unilateral Cortical Damage Involves the Remaining Hemisphere
}

\author{
T. M. Barth ${ }^{1}$ and B. B. Stanfield ${ }^{2}$ \\ 'Laboratory of Neurophysiology and 'Laboratory of Clinical Science, National Institute of Mental Health, National Institutes \\ of Health Animal Center, Poolesville, Maryland 20837
}

\begin{abstract}
Following unilateral lesions of the somatic sensorimotor cortex (SMC) in neonatal, but not adult, rats, an aberrant ipsilateral corticospinal projection originates from the undamaged hemisphere (Hicks and D'Amato, 1970; Leong and Lund, 1973; Castro, 1975). We have evaluated the contribution of the hemisphere contralateral to a unilateral lesion of the SMC in the recovery of tactile forelimb-placing behavior. Neither adult-lesioned or neonatally lesioned animals show evidence for placing deficits with either forelimb when tested 30 or $\mathbf{4 2} \mathrm{d}$ after the lesion. However, in adult-lesioned animals, a subsequent lesion of the undamaged SMC on postlesion day 42 produces placing deficits only with the forelimb contralateral to the second lesion, while such a second lesion in the neonatally lesioned rats results in placing deficits with both forelimbs. Anatomical observations in the animals used for behavioral analyses confirm previous reports of a substantial ipsilateral corticospinal projection in rats with unilateral SMC damage as neonates and demonstrate that many of these aberrant fibers recross the midline within the spinal cord to arborize extensively within the ipsilateral spinal gray. These findings indicate that, following unilateral SMC lesions in neonates, the contralateral hemisphere mediates some aspects of the recovery of forelimb placing. The aberrant ipsilateral corticospinal projection may provide the anatomical substrate through which the cortex effects this recovery.
\end{abstract}

For well over $100 \mathrm{yr}$, it has been recognized that recovery of function following early brain damage in many cases differs from the recovery, if any, that follows a similar injury to the adult nervous system (Broca, 1865; Vulpian, 1866; Soltmann, 1876; Freud, 1897; Brown, 1915; Weed, 1917; Langworthy, 1924, 1926; Kennard, 1936, 1938). While in most instances the neuroanatomical and neurophysiological correlates of these agerelated differences in recovery of function remain to be clarified, in some cases, candidate mechanisms are suggested by the greater capacity of the immature CNS for neural reorganization following damage. For example, following unilateral cortical lesions in neonatal rats, there are structural and functional changes

\footnotetext{
Received Jan. 29, 1990; revised Apr. 16, 1990; accepted June 25, 1990.

We would like to acknowledge the excellent technical assistance of Mrs. Darlene Brown. We also thank our colleague, Dr. Steve Wise, for his comments on an earlier version of this manuscript. A sample of fluoro-ruby was generously provided to us by Dr. L. C. Schmued.

Correspondence should be addressed to T. M. Barth, Department of Psychology, Texas Christian University, Forth Worth, TX 76129.

Copyright (C) 1990 Society for Neuroscience $0270-6474 / 90 / 103449-11 \$ 03.00 / 0$
}

in the remaining hemisphere that do not occur after adult lesions. Following a neonatal hemidecortication, the remaining cortex attains an increased thickness (Kolb et al., 1983; Kolb and Tomie, 1988) and exhibits altered connectivity. There is an increase in the ipsilateral corticospinal projection and increases in the crossed corticostriatal, corticothalamic, corticotectal, and corticopontine projections (Hicks and D'Amato, 1970, 1975; Leong and Lund, 1973; Castro, 1975; Leong, 1976; Kolb et al., 1983; Kartje-Tillotson et al., 1985, 1987; Sharp and Gonzalez, 1986; Kolb and Gibb, 1987; Kolb and Tomie, 1988; Whishaw and Kolb, 1988; Huttenlocher and Raichelson, 1989; Reinoso and Castro, 1989). These changes in the intact hemisphere of neonatally lesioned animals may reflect differences in the mechanism mediating postlesion recovery or sparing of function when compared to adult animals receiving similar lesions. (It should be noted that the absence of a deficit in a neonatally lesioned animal may, in the strictest sense, best be considered "sparing" of this function rather than "recovery," because the behavior had not yet developed at the time of the lesion. While recognizing this, for the convenience of presentation, we will use the term "recovery" to refer to a lack of deficit in behavioral functions that are either spared or recovered.)

Although there is little behavioral evidence to support the view that the intact cortex is involved in recovery from unilateral neonatal lesions, there is reason to belicve that it docs not have a role in the recovery of adult-lesioned animals. Several studies have shown that, following recovery from unilateral lesions in adults, a second lesion of the remaining hemisphere produces deficits only in the limbs contralateral to that second lesion (Kennard and Ectors, 1938; Norsell, 1967; Faugier-Grimaud et al., 1978; de Castro and Zrull, 1988; Barth et al., 1990b). While these observations indicate that the recovery from the initial adult lesion cannot be mediated solely by the unlesioned hemisphere, they of course do not rule out a role for the remaining hemisphere in the recovery following a similar neonatal lesion.

To test the involvement of the contralateral hemisphere (and perhaps the aberrant ipsilateral corticospinal projection) in the behavioral recovery that follows a unilateral neonatal lesion of the sensorimotor cortex (SMC), we measured the performance of neonatally lesioned and adult-lesioned rats, both before and after a second lesion of the remaining hemisphere, on tactile forelimb-placing tasks and on a bilateral tactile-stimulation test. The forelimb-placing task was chosen because there is considerable evidence to suggest that the corticospinal projection is involved in placing behavior (Brooks, 1933; Hicks and D'Amato, 1975; Donatelle, 1977; Reh and Kalil, 1982). Moreover, 
preliminary data suggest that rats receiving unilateral neonatal cortical lesions show recovery of certain placing behaviors when tested as adults. We hypothesized that if the unablated hemisphere mediates the recovery of placing behavior following unilateral neonatal cortical lesions, then a second lesion as an adult would produce impairments with both forelimbs. In contrast, the bilateral tactile-stimulation task was chosen because rats may not recover from the asymmetry that follows unilateral neonatal cortical lesions (Schallert and Whishaw, 1985). Finally, in both experimental and control animals, the presence of an aberrant ipsilateral corticospinal projection was evaluated anatomically.

\section{Materials and Methods}

\section{Animals and surgery}

Sprague-Dawley rats generated in our breeding colony at the NIH Animal Center were used for this study. Females with newborn litters were housed in separate cages. On the day of birth, 23 animals received a large unilateral lesion that involved the somatic sensorimotor cortex (SMC). Neonatal rats were anesthetized by hypothermia, and a bone flap was cut in the skull overlying the right hemisphere. The cortex was aspirated through a glass pipette. Following the lesion, the pups were returned to their mother, where they remained until postnatal day 22 . At that time, they were sorted by gender, housed in groups (4-5 per cage) in Plexiglas cages, and maintained on a 14:10-hr light : dark cycle. Food and water were freely available. On postnatal day 43 , the rats were anesthetized with chloral hydrate $(35 \mathrm{mg} / 100 \mathrm{gm}$ body weight, i.p.) for either a second cortical lesion $(n=15)$ in the contralateral (left) hemisphere [neonatal lesion/adult lesion group (NL/AL)] or a sham operation $[n=8(\mathrm{NL})]$.

Seven previously untreated young adult rats were ancsthetized with chloral hydrate on postnatal day 43 and received an initial unilateral cortical lesion with a procedure essentially identical to that described above. All of these animals [adult lesion/adult lesion (AL/AL)] received a second lesion in the remaining hemisphere between postnatal days 86-88.

\section{Behavioral tests}

All behavioral testing was performed in the animal colony room, because the animals respond better there, rather than after being moved to a testing room. Tests were administered during the light portion of the light: dark cycle. The rats receiving unilateral cortical lesions as neonates were tested on postnatal days 30 and 42 . These data were combincd to provide a baseline. The battery of tasks was also administered on the $3 \mathrm{~d}$ immediately following the second surgery. Four animals in the NL/AL group received the tests on additional days (postoperative days $7,14,21,28$ ) in order to evaluate the pattern of behavioral recovery.

Rats receiving the initial lesion as adults were tested $1 \mathrm{~d}$ after the first lesion. These animals were again tested 30 and $42 \mathrm{~d}$ after this surgery (postnatal days 73,85 ), and the data from these tests were combined to provide a baseline for the adult-lesioned group. Finally, the rats in the AL/AL group were tested on the $3 \mathrm{~d}$ immediately following the second lesion.

Tactile forelimb placing. This forelimb-placing task consisted of 2 phases of testing. In both phases of this test, the animals were held by the trunk above the hindquarters such that their forelimbs could move frecly. Initially, testing was performed under red light and also under ambient light in order to evaluate the possibility that placing reactions were in response to visual as opposed to tactile cues. There was no evidence to suggest that the 2 light settings affected task performance.

In the first phase of testing, the animals were oriented with their head toward a Plexiglas surface, such that both forelimbs had equal opportunity to make a placing reaction (i.e., head-on placing task). Forelimb placing is defined as lifting the forelimb and placing it down on the surface. The animals were slowly moved forward until the vibrissae on both sides of the body contacted the Plexiglas surface. In intact animals, tactile stimulation of the vibrissae on both sides elicited a placing response from either forelimb with equal frequency or, on occasion, simultaneous placing of both forelimbs. In cortically damaged rats, this test measured preference for placing a particular forelimb (i.e., unilat- erally lesioned rats may show a preference to place with the forelimb ipsilateral to the lesion) or the complete absence of placing reactions with the forelimbs (i.e., in the case of rats with cortical lesions in both hemispheres, there may be a placing deficit with both forelimbs). For each of 10 trials, the placing reaction was evaluated as 1 of the following: the right forelimb placed before the left, the left forelimb placed first, both forelimbs placed simultancously, or no placing rcaction with cither forelimb.

In the second phase, each forelimb was independently tested for placing reactions by orienting either the left or right side of the animal toward the surface and slowly moving the animal until the vibrissae on that side touched the Plexiglas (i.e., vibrissae $\rightarrow$ forelimb-placing task). In intact animals, stimulation of the vibrissae reliably elicited a placing response with the ipsilateral forelimb. On each test day, the animals received $\mathbf{1 0}$ trials for the left and 10 trials for the right forelimb.

Foot-fault test. Animals were placed on an elevated $(8.5-\mathrm{mm})$ grid floor $(34 \times 29 \mathrm{~mm})$ for $2 \mathrm{~min}$. The openings in the grid were $2.2 \times 2.2$ $\mathrm{cm}$, and the caliber of the grid wires was $2 \mathrm{~mm}$. Previous work has shown that intact animals place their paws on the wire frame or foot holds while moving around on the grid (Barth et al., 1990). Occasionally, intact animals inaccuratcly placed a fore- or hindlimb, and it fell through 1 of the openings in the grid (i.e., a "foot fault"). Limb misplaces in control animals, though infrequent, were typically symmetrical (tended to occur equally often with either the left or right limb). The dependent variables were the number of foot faults for each fore- and hindlimb. Finally, the number of forelimb steps was recorded in order to evaluate the possibility that any differences in group performance were due to significant differences in general activity.

Bilateral tactile-stimulation test. This procedure has been described in detail in previous papers (Schallert et al., 1982; Schallert and Whishaw, 1984). Briefly, for each trial, small adhesive-backed patches (113.1 $\mathrm{mm}^{2}$ ) were applied to the radial aspect of both forelimbs. Rats were handled gently for $3-4 \mathrm{~d}$ before testing such that the patches were easily applied without causing apparent distress to the rat. Indeed, the rats were sufficiently tame that it was possible to apply the patches in 5-10 sec. The rats were placed back into their home cage, and the order of contact/removal (i.e., left vs. right) as well as the latencies to contact and remove the patches were recorded. The patches were removed by bringing the forelimb up to the mouth and pulling off the patch with the teeth. A trial ended when the rat removed both patches or after 3 min. Four or 5 trials were given to each rat on each test day.

Previous studies have shown that rats receiving unilateral cortical or dopamine depletions of the striatum as adults typically contact the patch on the forelimb ipsilateral to the brain lesion on $100 \%$ of the trials (Schallert et al., 1982; Schallert and Whishaw, 1984; Barth and Schallert, 1987) immediately after surgery (i.e., ipsilateral bias). Rats receiving hemidecortications on the day of birth also show an enduring ipsilateral bias (Schallert and Whishaw, 1985).

\section{Anatomical studies}

Three $\mathrm{d}$ following the second surgery (either lesion or sham), all the behaviorally tested animals (except the $4 \mathrm{NL} / \mathrm{AL}$ animals tested at longer postlesion survival times) were anesthetized with an overdose of chloral hydrate and exsanguinated while perfused intracardially with $0.9 \% \mathrm{NaCl}$ followed by $10 \%$ neutral buffered formalin. The brains and spinal cords were removed, and the success of the lesions was evaluated by gross examination of the damage to the cortical surface and, subsequently, in the stained sections.

The lower medulla and spinal cord were frozen sectioned horizontally at $40 \mu \mathrm{m}$, and a 1 -in-3 series of sections was collected and later stained with a modification of a silver-impregnation method for the detection of axonal and terminal degeneration (Kalaha-Brunst et al., 1974). The remainder of the brain was frozen sectioned coronally and two 1-in-10 series were collected. One of these series was silver stained in the same manner as the spinal cord sections, and the other was processed through a routine Nissl stain using thionin.

Seven additional animals were used solely for anatomical experiments. Five of these received SMC lesions on the day of birth in the same manner as the cases described above. On postnatal day 45 , all 7 animals were anesthetized with chloral hydrate and secured in a Kopf stereotaxic device. Fifteen to $200.1-\mu$ l injections of $10 \%$ fluoro-ruby (Schmued and Heimer, 1989; Schmued et al., 1990) were placed in the SMC on the undamaged side. The injections were spaced $1 \mathrm{~mm}$ apart throughout the motor and somatosensory cortex at a depth of $1.5 \mathrm{~mm}$. After a 3-week survival period, the animals were deeply anesthetized 


\begin{tabular}{lcccc}
\hline Table 1. & Forelimb placing: head-on task & & \\
Group & Ipsilateral first & Contralateral first & Simultaneous & No response \\
\hline Baseline & & & & \\
NL/AL & $19.1 \pm 5.8$ & $60.0 \pm 8.1$ & $20.9 \pm 5.1$ & $0.0 \pm 0.0$ \\
AL/AL & $10.7 \pm 8.5$ & $89.3 \pm 8.5$ & $0.0 \pm 0.0$ & $0.0 \pm 0.0$ \\
NL & $17.5 \pm 7.7$ & $80.0 \pm 8.3$ & $2.5 \pm 1.6$ & $0.0 \pm 0.0$ \\
After second & & & & \\
surgery & & & & \\
NL/AL & $33.9 \pm 8.3$ & $27.6 \pm 5.1$ & $5.8 \pm 1.7$ & $32.7 \pm 9.6$ \\
AL/AL & $30.5 \pm 6.8$ & $1.4 \pm 1.0$ & $4.3 \pm 4.3$ & $63.8 \pm 6.2$ \\
NL & $5.4 \pm 3.1$ & $93.8 \pm 3.2$ & $0.0 \pm 0.0$ & $0.8 \pm 0.8$ \\
\hline
\end{tabular}

Values shown are mean percent \pm SEM.

with chloral hydrate and exsanguinated while perfused intracardially with $0.9 \% \mathrm{NaCl}$ followed by $10 \%$ neutral buffered formalin, and the brain and spinal cord were removed. A 1 -in- 10 series of $40-\mu \mathrm{m}$ frozen sections was collected through the brain (sectioned coronally) and spinal cord (sectioned transversely). These sections were mounted on glass slides and coverslipped for subsequent examination on a fluorescence microscope.

\section{Results}

\section{Recovery from unilateral cortical damage}

Lesions as adults. Preoperative observations in young adults showed that animals responded in $100 \%$ of the trials in both the vibrissae $\rightarrow$ forelimb and head-on placing tasks. Moreover, on the foot-fault test, the animals made no faults with the left forelimb and a mean of $0.6 \pm 0.3 \mathrm{SEM}$ with the right forelimb.

One $d$ following the initial unilateral cortical lesion in the right hemisphere, the adult-lesioned animals continued to place with the forelimb ipsilateral to the lesion on the vibrissae $\rightarrow$ forelimb-placing task on all trials. In contrast, none of these rats made a single successful placing response with the forelimb contralateral to the lesion. Postoperative results of the head-on placing task were a bias to place with the forelimb ipsilateral to lesion on $100 \%$ of the trials. A deficit with the contralateral forelimb was also observed on the foot-fault test. Performance on this test changed from $0.6 \pm 0.3$ faults before surgery to an average of $4.4 \pm 0.4$ in the 2 -min observation period on the day after the lesion. There was no postoperative change with the forelimb ipsilateral to the lesion. Finally, as expected, these animals showed an ipsilateral preference on the bilateral tactilestimulation task. Rats contacted the adhesive patch on the forelimb ipsilateral to the lesion on $100 \%$ of the trials $1 \mathrm{~d}$ after surgery. The median latencies to contact the adhesive patches were $2.0 \mathrm{sec}$ (rangc, 1.0-5.5 sec) and 19.5 sec (range, 12.5-199.0 sec) for the ipsilateral and contralateral patches, respectively.

Performance on the forelimb-placing tasks returned to nearpreoperative levels on postoperative days 30 and 42 . On the vibrissae $\rightarrow$ forelimb-placing task, the adult-lesioned rats failed to respond with the forelimb contralateral to the lesion on only $19.3 \pm 10.7 \%$ of the trials. Moreover, by $42 \mathrm{~d}$ after surgery, only 1 of the 7 animals showed unsuccessful contralateral placements. Although there was still an ipsilateral preference for placing in the head-on task, the bias was slightly less severe (mean percent of trials with ipsilateral placements first, $89.3 \pm 8.5 \%$; Table 1). Finally, the mean number of contralateral-forelimb foot faults dropped to $1.4 \pm 0.4$ in the 2 -min observation period (see Fig. 2).
In contrast to the recovery in forelimb-placing behavior, performance on the bilateral-stimulation task only slightly changed over time. On postoperative days 30 and 42 , the rats contacted the patch ipsilateral to the lesion first on $93.6 \pm 4.2 \%$ of the trials. The median latencies to contact the adhesive stimuli were $14.0 \mathrm{sec}$ (range, 5.0-18.3 sec) for the contralaterally placed patch and $1.0 \mathrm{sec}$ (range, $1.0-4.0 \mathrm{sec}$ ) for the ipsilaterally placed stimulus.

Lesions as neonates. The behavior of neonatally lesioned rats on postoperative d 30 and 42 was similar to that observed in adult-lesioned animals tested during the same postoperative time period. Rats receiving lesions as neonates were unsuccessful in placing with the ipsilateral forelimb on only $0.5 \pm$ $0.5 \%$ of the trials (Fig. 1). Similar to the adult-lesioned animals, rats receiving lesions as neonates exhibited a preference for placing with the ipsilateral forelimb on the head-on task (mean percent of trials with ipsilateral placements first, $68.4 \pm 6.2 \%$ ). The mean number of foot faults was $1.2 \pm 0.3$ with the contralateral forelimb and $0.6 \pm 0.1$ with the forelimb ipsilateral to the lesion. Finally, neonatal cortical lesions produced an ipsilateral bias on the bilateral-stimulation task (the patch on the forelimb ipsilateral to the lesion was contacted first on $95.1 \pm$ $2.2 \%$ of the trials; see Fig. 4). The median latencies to contact the adhesive patches were $3.5 \mathrm{sec}$ (range, 1.0-150.5 sec) on the ipsilateral forelimb and $25.8 \mathrm{sec}$ (range, $3.5-152.3 \mathrm{sec}$ ) for patches placed on the contralateral forelimb. There were no statistically significant differences between the performances of the neonatal- and adult-lesion groups on these postoperative test days.

\section{The effects of a second lesion in the remaining hemisphere}

Vibrissae $\rightarrow$ forelimb-placing task. Consistent with an earlier study (Barth et al., 1987), the AL/AL rats showed a forelimb-placing deficit only with the forelimb contralateral to the second lesion. In contrast, the NL/AL group had impairments with both forelimbs on this task after the second surgery. Rats that received a sham lesion as adults showed no change in behavior after the second surgery.

As shown in Figure $1 B$, both the $\mathrm{AL} / \mathrm{AL}$ and the $\mathrm{NL} / \mathrm{AL}$ groups failed to place with the forelimb contralateral to the second lesion on the majority of trials. One-way analysis of variance (ANOVA) revealed a significant effect among groups $(F=131.94, p<0.01)$. Post hoc Scheffe's tests suggested that the NL group placed on significantly more trials than either the NL/AL $(F=97.05, p<0.05)$ or AL/AL group $(F=103.4, p$ 
A

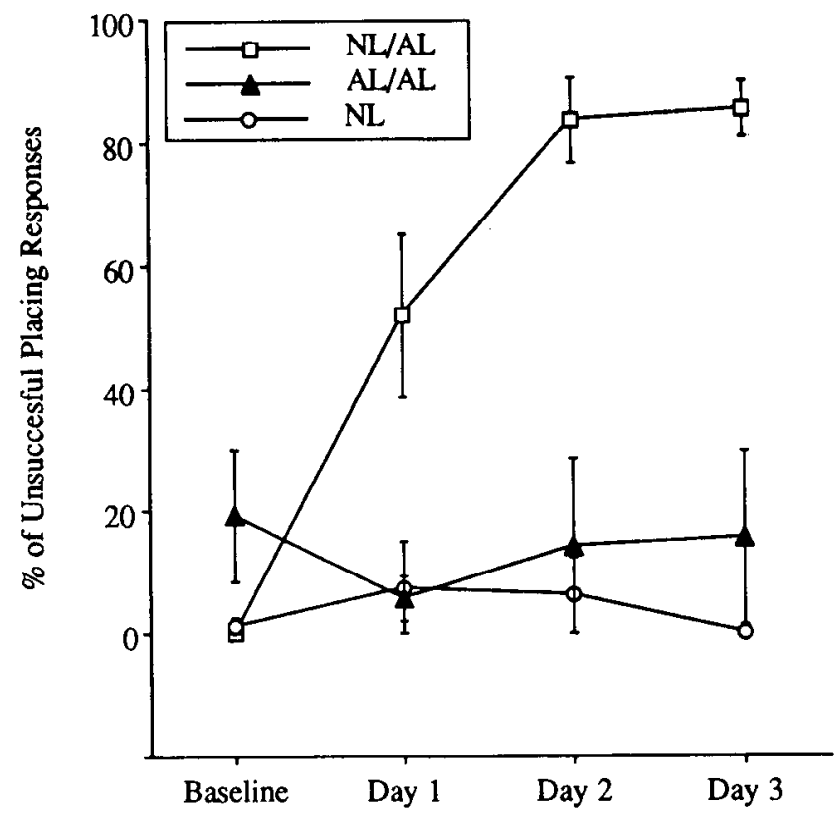

B

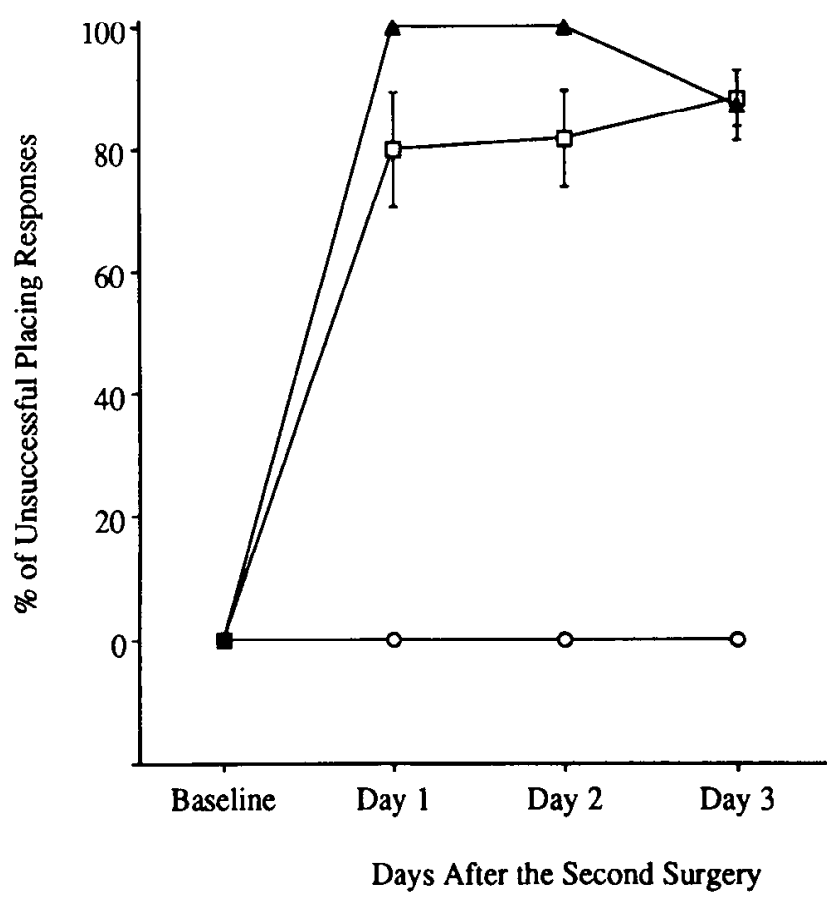

Figure 1. Performance on vibrissae $\rightarrow$ forelimb-placing task before and after second lesion in different lesion groups. Tests administered shortly before the second surgery (i.e., baseline) showed that there were no placing deficits in any of the lesion groups. However, following the second surgery, rats in the NL/AL group were unsuccessful in placing the forelimbs both ipsilateral $(A)$ and contralateral $(B)$ to the second lesion. After the second lesion, rats in the AL/AL group exhibited a placing impairment only with the forelimb contralateral to the second lesion $(B)$. Rats in the NL group failed to show placing deficits on this task. Error bars indicate SEM.
$<0.05)$. Finally, there was no statistically significant difference between the NL/AL and AL/AL groups $(F=2.0, p>0.05)$.

The mean percentage of unsuccessful placements with the forelimb ipsilateral to the second lesion is shown in Figure $1 \mathrm{~A}$. Only the NL/AL rats showed a significant impairment in placing the ipsilateral forelimb. This difference among groups was statistically significant $(F=30.7, p<0.01)$.

Placing deficits were observed with both the ipsilateral and contralateral forelimb for at least $28 \mathrm{~d}$ in the NL/AL rats that received the additional tests. One week after the second lesion, these rats failed to place either forelimb in response to the vibrissae stimulation. Moreover, on postoperative day 14 , the rats were unsuccessful in placing the forelimb ipsilateral to the second lesion on $90 \%$ of the trials and on $100 \%$ of the trials with the contralateral forelimb. By the fourth week, there was some recovery with both forelimbs. The mean percentage of unsuccessful trials was $45 \%$ with the ipsilateral and $55 \%$ with the contralateral forelimb.

Head-on placing task. The results of the head-on placing task are shown in Table 1 . The second lesion produced a significant reduction in the number of placing responses in both the NL/ $\mathrm{AL}$ and $\mathrm{AL} / \mathrm{AL}$ groups. ANOVA indicated a significant overall group effect $(F=14.4, p<0.01)$. Post hoc comparisons suggested that both the NL/AL and AL/AL groups were different from the NL group ( $p<0.05$ for both comparisons). Moreover, the reduction of placing was significantly greater in the $A L / A L$ group (Scheffe's $F=4.0, p<0.05$ ).

Foot-fault test. As shown in Figure 2, the second lesion produced an increase in the number of misplaces with both forelimbs in the NL/AL group and only with the forelimb contralateral to the second lesion in the $\mathrm{AL} / \mathrm{AL}$ group. There was no postoperative change after the second surgery in the NL rats. There were statistically significant group differences in the mean number of ipsilateral and contralateral foot faults $\left(F_{\mathrm{ipsi}}=9.7, p\right.$ $\left.<0.01 ; F_{\text {contra }}=16.1, p<0.01\right)$. Significant differences in the number of ipsilatcral faults were found between the NL/AL and AL/AL groups (Scheffe's $F=98.7, p<0.05$ ). However, these 2 groups did not differ in the number of faults made with the forelimb contralateral to the second lesion $(F<1)$. The NL group was statistically different from both the NL/AL and AL/ AL rats ( $p<0.05$ in both cases), but only from the NL/AL animals in the number of ipsilateral faults $(F=4.5, p<0.05)$. Finally, there were no significant differences among the groups in the number of forelimb steps.

The bilateral impairment on the foot-fault test endured for at least 3 weeks following the second surgery in NL/AL rats. On day 21 , these rats made a mean of 2.3 faults with the forelimb ipsilateral to the adult lesion and 2.8 contralateral misplacements. However, the deficits were almost completely gone by day 28 ( 0.75 faults with each forelimb).

Bilateral tactile-stimulation task: latencies to contact adhesive patches. After the second surgery, rats in the NL/AL and AL/ AL groups were slow to contact the contralaterally placed patch. The median latencies to contact the contralateral patch were $31.0 \mathrm{sec}$ (range, 18.0-180 sec) for the NL/AL animals and 39.0 sec (range, 10.0-180 sec) for the AL/AL group (Fig. 3). When compared to the NL rats, these differences in latencies to contact were statistically significant (Kruskal-Wallis $H=16.0, p<0.01$ ). There was no statistically significant difference between the contralateral latencies of the $N L / A L$ and $A L / A L$ rats (Mann-Whitney $U=3.75, p>0.05$ ).

Latencies to contact the patch on the forelimb ipsilateral to the second lesion also differed among the 3 groups $(H=10.9$, 


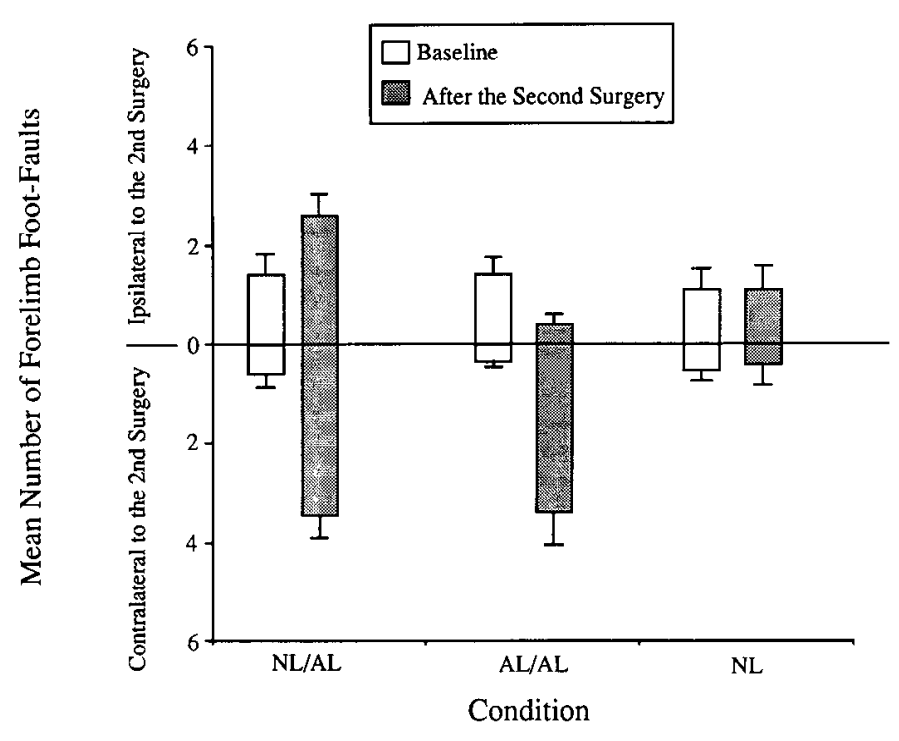

Figure 2. Performance on foot-fault test before and after second lesion in different lesion groups. There were no foot-fault deficits in any of the groups when tested shortly before the second surgery. Following the second lesion, rats in the NL/AL group made foot faults with both forelimbs, whereas the AL/AL group only misplaced the forelimb contralateral to the second lesion. Error bars indicate SEM.

$p<0.05$ ). Rats in the NL/AL group contacted the ipsilateral patch in a median latency of $12.5 \mathrm{sec}$ (range, 8.5-30.0 sec), whereas the latencies for the AL/AL and NL groups were 2.5 sec (range, 1.0-16.0 sec) and $6.8 \mathrm{sec}$ (range, 4.0-11.5 sec), respectively. However, it should be noted that this difference between groups does not reflect an increase in the ipsilateral latencies for the NL/AL rats (baseline, $25.8 \mathrm{sec}$ ). Indeed, all 3 groups showed decreased latencies to contact the ipsilateral patch after the second surgery.

Bilateral tactile-stimulation task: test for asymmetry. Rats in the NL/AL and AL/AL groups contacted the patch placed on the forelimb ipsilateral to the second lesion first on over $90 \%$ of the trials. These results were significantly different from the NL rats that continued to show a bias ipsilateral to the first lesion $(F=135.9, p<0.001)$. These data are shown in Figure 4.

\section{Anatomical observations}

The brains and spinal cords of all of the animals which underwent behavioral testing were processed for histological examination. Both the neonatal and adult lesions included (but were not restricted to) large lesions of the SMC, and there was no systematic difference among the groups in the extent or the placement of the lesions (Fig. 5). In most cases, the entire primary somatosensory cortex and motor cortex were damaged. The majority of animals also had damage in the secondary somatosensory cortex. The following were completely or mostly spared: the prelimbic, cingulate, retrosplenial, lateral insular, and visual areas in the occipital cortex. In all cases, the subcortical white matter was damaged, but the lesions rarely extended into the caudate nucleus or hippocampus.

In addition to evaluating the extent of cortical damage, wc wanted to be able to determine anatomically whether or not an aberrant ipsilateral corticospinal projection was present in our experimental animals. Unfortunately, the experimental design for the behavioral testing involved lesioning the cortical hem-

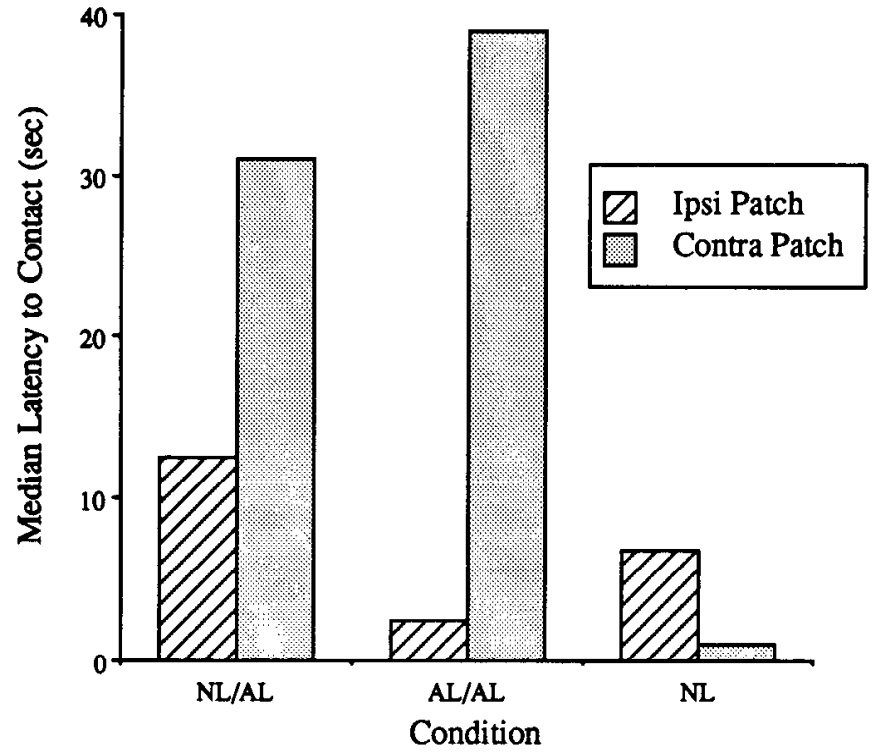

Figure 3. Latencies to contact adhesive stimuli in different lesion groups.

isphere whose spinal projection we wished to examine, thus precluding the use of the most modern neuroanatomical tracers. We therefore relied on a silver-stain-degeneration technique to examine the corticospinal pathway in these animals. However, because the aberrant ipsilateral corticospinal projection from the hemisphere remaining after a neonatal cortical lesion in rats has not been examined with any of the presently available anterograde neuroanatomical tracers that give resolution of the individually labeled axons, we first prepared 7 additional cases ( 5 with neonatal cortical lesions and 2 with no prior lesions) in which a rhodamine-conjugated dextran derivative (fluoro-ruby) was used to trace the corticospinal projection (Schmued and Heimer, 1989; Schmued et al., 1990).

The distribution of fluoro-ruby-labeled corticospinal fibers in our control rats resembles previously described corticospinal projections (Brown, 1971; Antal, 1984; Gemma et al., 1987; Gribnau and Dederen, 1989). Whereas just below the level of the pyramidal decussation some ectopic labeled axons are seen, by midcervical lcvels, virtually all of the labeled corticospinal axons are contralateral to the injected cortex and confined to a wedge-shaped bundle in the ventral portion of the dorsal funiculus. No labeled axons are seen at this level within the dorsal funiculus ipsilateral to the injected cortex. Within the spinal gray, the labeled fibers arborize extensively within the dorsal horn, especially within the deeper laminae and adjacent to the dorsal funiculus.

The distribution of labeled corticospinal fibers from the left cortex is notably different in adult animals in which a large lesion had been made in the right rostral cortex on the day of birth. Still, the vast majority of fluoro-ruby-labeled corticospinal axons within the cervical cord in these cases is again confined to a bundle within the dorsal funiculus. As a result of the absence of an opposite corticospinal tract, this bundle is bowed across the midline (Figs. 6, 7). More importantly, within the spinal cord, 2 types of aberrant fluoro-ruby-labeled corticospinal axons are seen in these cases. The first are a few fluoro-ruby-labeled axons that travel within the dorsal funiculus ipsilateral to the injected cortex (Figs. 6A,B,7), and the second are fluoro-rubylabeled axons that can be followed from the main bundle of 


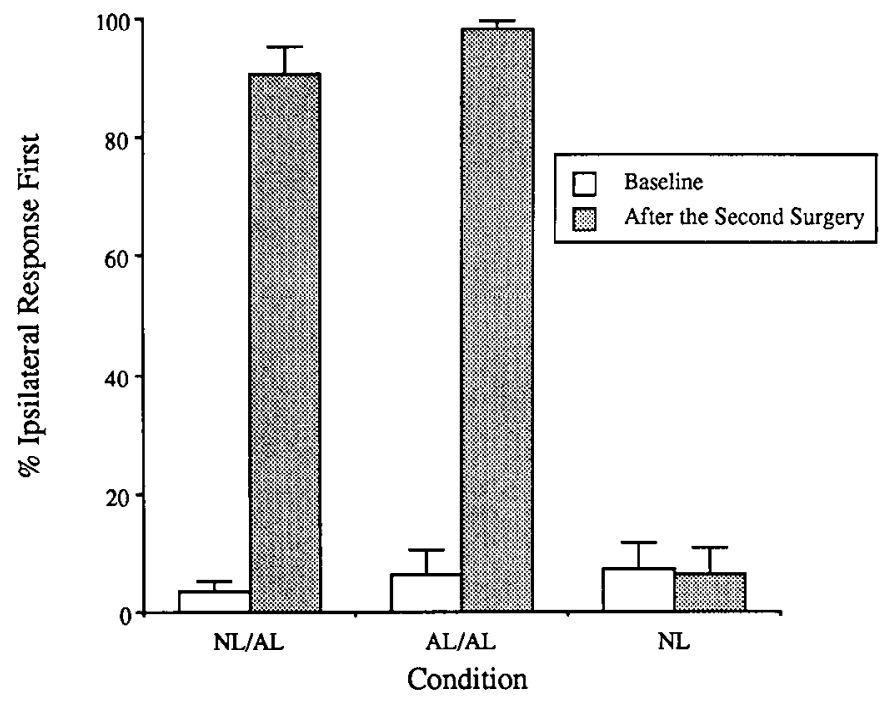

Figure 4. Performance of lesion groups on the bilateral tactile-stimulation test. Unilateral SMC lesions produced an ipsilateral somatosensorimotor asymmetry in rats receiving lesions as neonates or adults. This is shown in the baseline data as the percent of trials that the stimulus ipsilateral to the second lesion was contacted first (i.e., a very small percentage reflects a bias ipsilateral to the second lesion). The second lesion reversed the asymmetry in rats in the NL/AL and the AL/AL groups. That is, the animals in these 2 groups now contacted the stimulus ipsilatcral to the sccond lesion first on morc than $90 \%$ of the trials. Error bars indicate SEM.

labeled corticospinal axons, across the midline, and into the spinal gray of the dorsal horn ipsilateral to the injected cortex (Fig. 6). In our material, these latter axons seem to contribute the majority of fibers to the aberrant ipsilateral corticospinal projection. It should also be noted that these axons cross the midline twice: once, presumably, at the pyramidal decussation, and a second time within the spinal cord near their level of termination. The aberrant ipsilateral corticospinal fibers branch rather widely within the dorsal horn ipsilateral to the injected cortex (Fig. 7) and give rise to what seem to be terminal arbors (Fig. 6C). These observations confirm the earlier reports of an aberrant ipsilateral corticospinal projection following early unilateral cortical damage and suggest that most of the fibers that contribute to this projection travel in the contralateral dorsal funiculus, then recross the midline within the spinal cord.

The results from our silver-stain-degeneration material are quite straightforward. In animals with no previous lesions, a cortical lesion gives rise to degeneration within the contralateral dorsal funiculus and spinal gray, but there is virtually no evidence for degeneration within the spinal cord ipsilateral to the lesion (Fig. 8). In animals with neonatal cortical lesions, a second lesion in the remaining hemisphere gave rise to fine, dustlike silver degeneration within the dorsal horn on both sides of the spinal cord (Fig. 9). It should be noted that it was confirmed in 8 neonatally lesioned animals without a second lesion that no stainable degeneration products from the initial lesion are present at the interlesion interval used. Finally, in animals that received both lesions as adults, fine, dustlike silver degeneration is seen only contralateral to the second lesion (Fig. 10). Unlike the case after neonatal lesions, however, some of the degeneration products of the initial lesion in these animals are still present at these survival times. These, however, are very coarse
A B
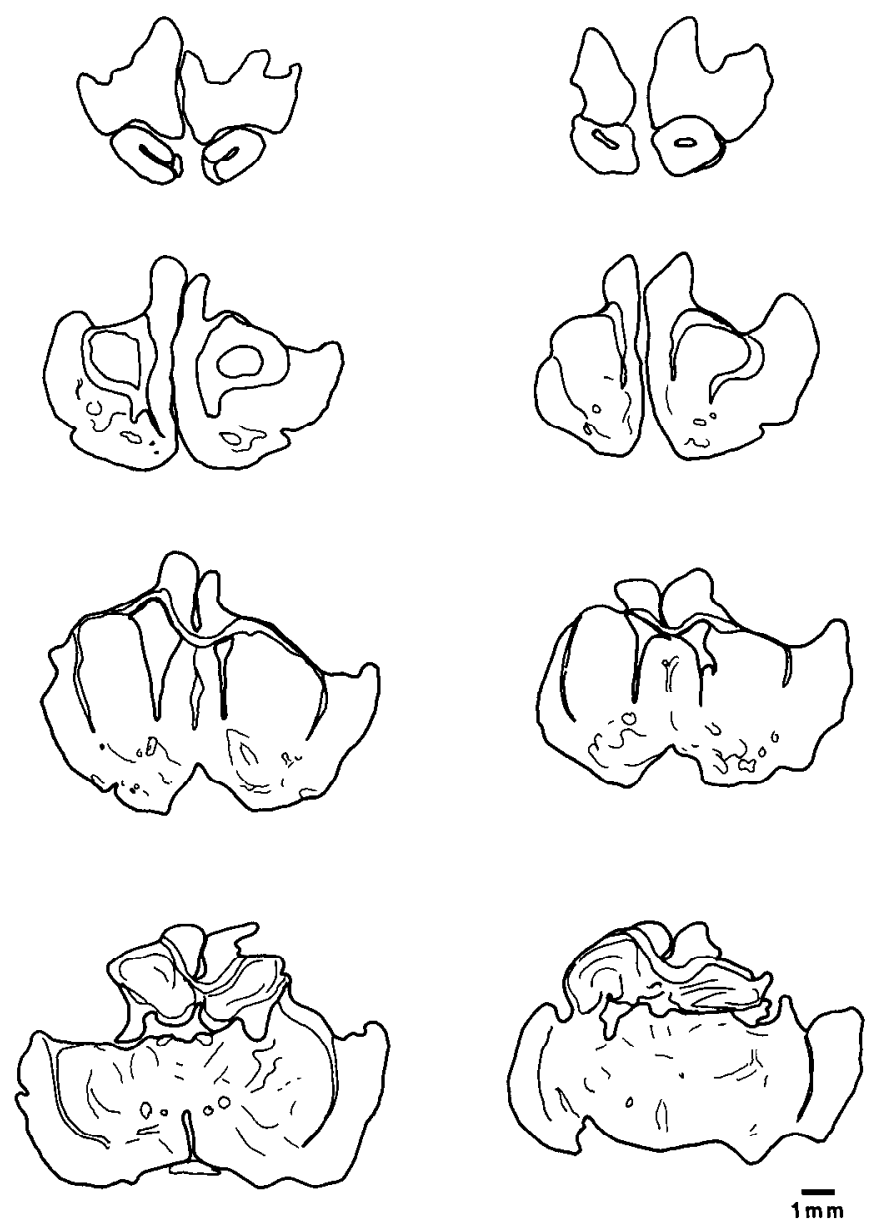

Figure 5. Camera lucida drawings of representative lesions. $A$, An animal that received both lesions as an adult (AL/AL). $B$, An animal that received the first lesion as a neonate (NL/AL). These are coronal sections from rostral (top) to caudal (bottom) spaced approximately 2.2 $\mathrm{mm}$ apart, with the first lesion in the left hemisphere. There are no systematic differences in the lesion size or location between groups.

and fibrous and are easily distinguishable from the fine terminal degencration causcd by the sccond lesion.

\section{Discussion}

The principal finding of this study is that, following unilateral neonatal SMC lesions, a lesion of the remaining SMC produces bilateral impairments in 2 forelimb-placing tasks, whereas following unilateral SMC lesions in adults, a lesion of the intact SMC results in deficits only with the forelimb contralateral to the second lesion. These observations suggest a major age-related difference in the mechanisms underlying recovery of function following unilateral cortical damage. The remaining hemisphere appears to be implicated in the recovery that follows an early lesion, but not in the recovery seen after an adult lesion. An anatomical correlate of this difference is provided by our confirmation of an aberrant ipsilateral corticospinal projection in the neonatally lesioned, but not in the adult-lesioned, animals. 


\section{Forelimb-placing deficits following unilateral SMC lesions}

While in the long-term there is recovery of function following both neonatal and adult unilateral SMC lesions, in adult rats such lesions produce several different acute placing deficits. For example, transient impairments in forelimb placing are observed in response to tactile stimulation of the vibrissae or during exploratory locomotion. These results appear to be contrary to previous reports suggesting forelimb placing was permanently disrupted by SMC lesions (Brooks, 1933; Hicks and D'Amato, 1975). However, in at least 1 of these earlier studies (Hicks and D'Amato, 1975), placing reactions were elicited with tactile stimulation of the forelimb rather than the vibrissae. Preliminary data confirm that this is a significant methodological difference. Adult rats $(n=4)$ receiving SMC lesions show recovery of placing within 2 weeks when vibrissae stimulation elicits forelimb placing (i.e., vibrissae $\rightarrow$ forelimb placing), but show no signs of recovery when the reaction is in response to tactile stimulation of the ulnar aspect of the forelimb (forelimb $\rightarrow$ forelimb placing) for at least 4 months. These data are consistent with a recent report (De Ryck et al., 1989) that found persistent limb-placing deficits in response to tactile stimulation of the forelimb that could be overcome by sensory stimulation arising from the head (whisker and/or chin). Thus, the more enduring placing deficit may reflect an impairment in forelimb tactile sensitivity and the vibrissae $\rightarrow$ forelimb-placing deficit may be viewed as a transient impairment in motor control. Alternatively, it may be suggested that the rats learn to use visual cues to guide the placing response in the vibrissae $\rightarrow$ forelimb task, and that this accounts for the apparent recovery of function. This is unlikely because tests administered under red light, which minimizes or eliminates visual cues, does not affect performance on the vibrissae $\rightarrow$ forelimb task. Finally, the nature of the placing dysfunction observed during exploratory locomotion is less clear. Although in a previous study (Barth et al., 1990b) it was suggested that impairments on the foot-fault test are a problem in proprioception, consistent with a general defect in somesthesia, this possibility needs further study.

Rats receiving unilateral SMC lesions as neonates did not show impairments in vibrissae $\rightarrow$ forelimb placing or forelimb placing during exploratory locomotion as tested on postnatal days 32 and 43 . The present study cannot address the issue of whether the lack of deficits on these tasks reflect recovery of a lost function or a sparing of the placing reactions. However, similar to the adult-lesioned animals, forelimb $\rightarrow$ forelimb placing is disrupted by neonatal lesions. Moreover, the placing deficit is still apparent 4 months after the time of the injury, which is also the case with the adult-lesioned animals. Thus, the longterm effects of unilateral SMC lesions appear to be the same in both neonatally and adult-lesioned animals.

\section{Recovery in rats lesioned as neonates or adults}

The behavioral performance of animals that receive unilateral cortical lesions as neonates depends largely on the tasks employed (Kolb and Holmes, 1983; Kolb et al., 1983; Kolb and Whishaw, 1985; Kolb and Tomie, 1988; Whishaw and Kolb, 1988; Kolb and Whishaw, 1989). This suggests that, while the anatomical plasticity apparent after neonatal lesions may be important for the recovery of some behaviors, it may be detrimental or inconsequential for others. We have found evidence that suggests the intact SMC is mediating the recovery of some tactile-placing reactions of the forelimb. However, in another
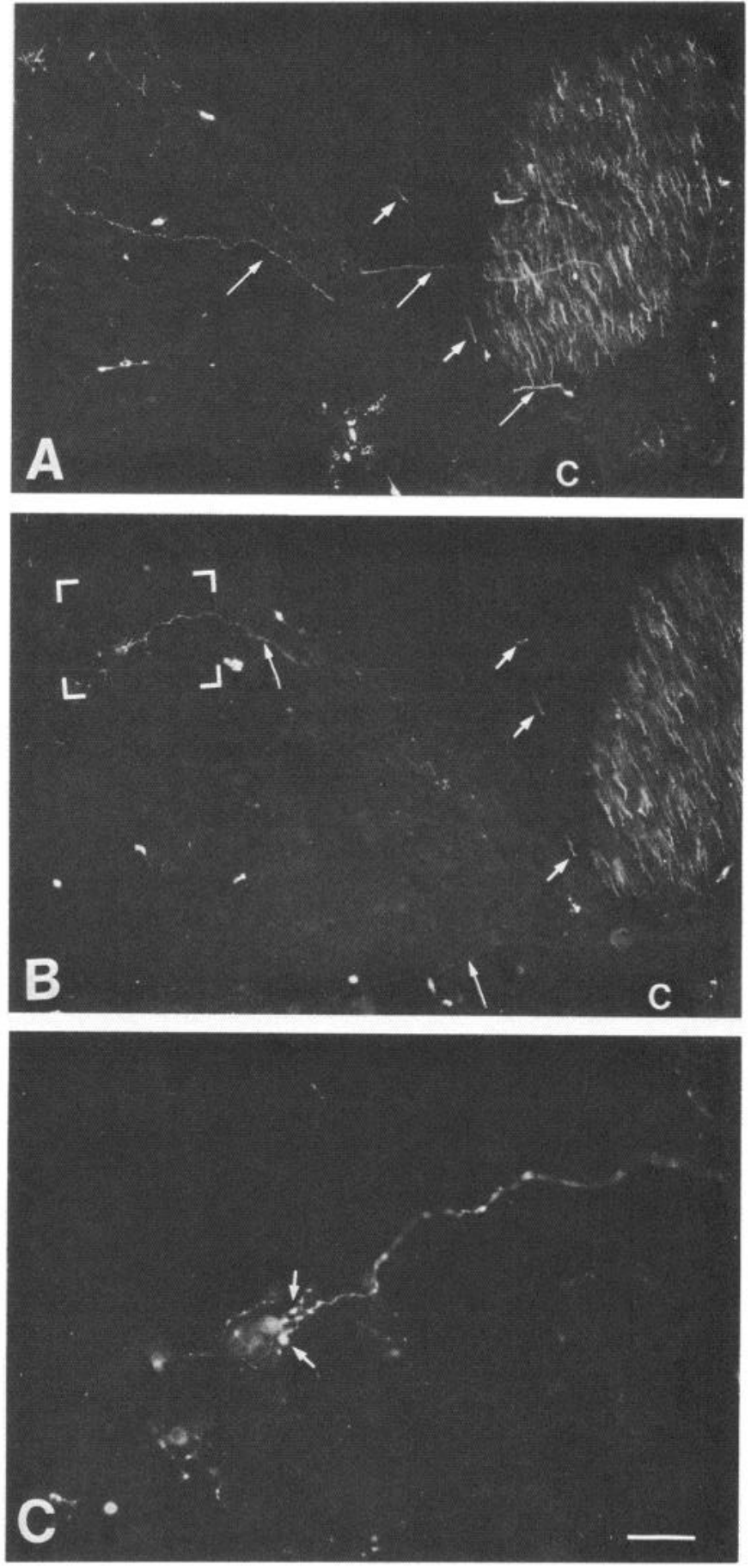

Figure 6. Fluorescence photomicrographs of transverse sections through cervical spinal cord of an animal that received a neonatal ablation of the right rostral cortex on the day of birth and was injected with the anterograde tracer fluoro-ruby into the left cortex on postnatal d 45. $A$ and $B$, While most of the fluoro-ruby-labeled corticospinal axons are in the dorsal funiculus contralateral to the injected cortex, which in these lesioned animals bows over the central canal (c), some can be seen traveling down the ipsilateral dorsal funiculus (short arrows), and some can be seen coursing across the section from the contralateral spinal cord to the opposite side (long arrows). $C$, This higher-magnification view of the region of the ipsilateral dorsal horn indicated in $B$ shows an aberrant ipsilateral corticospinal axon that branches and ends in beads that may be synaptic terminals (arrows). Scale bar, $100 \mu \mathrm{m}$ in $A$ and $B ; 20 \mu \mathrm{m}$ in $C$. 


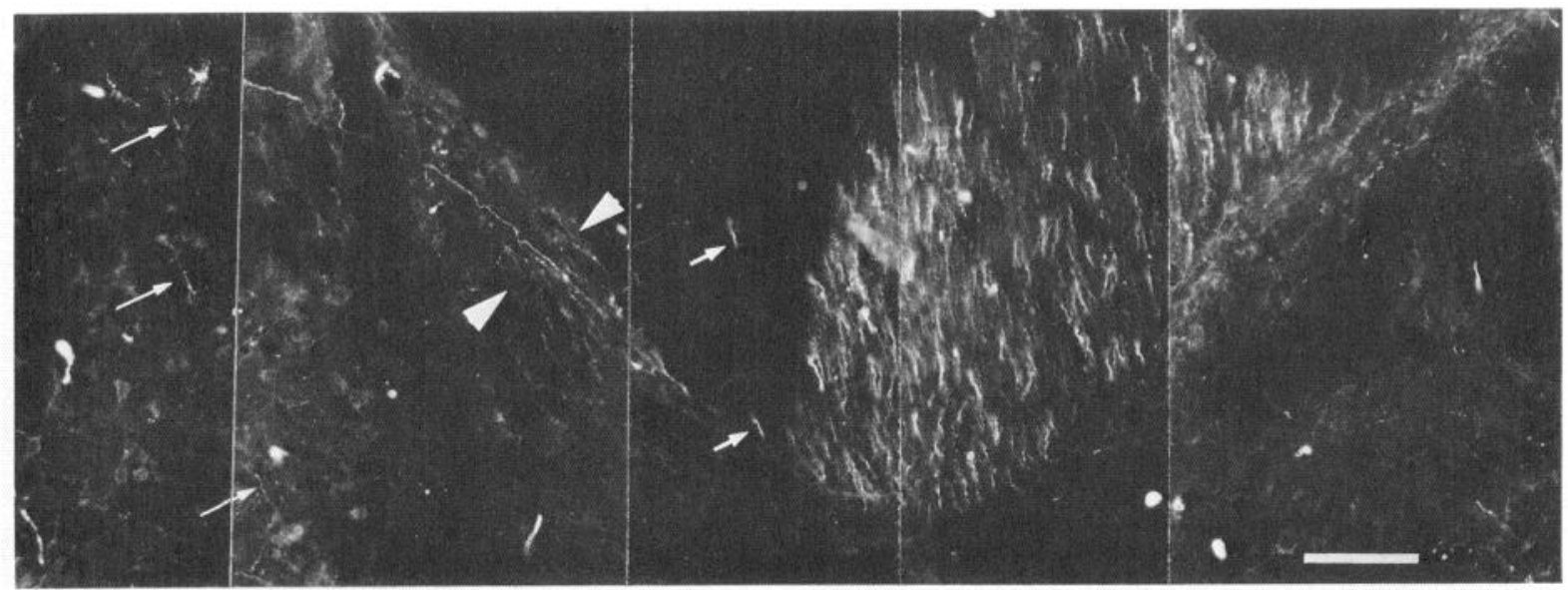

Figure 7. Fluorescence photomontage from a transverse section through the cervical spinal cord of an adult animal that had received a large cortical lesion as a neonate. Corticospinal axons from the remaining cortex are labeled with fluoro-ruby. Only a few labeled fibers are seen descending within the ipsilateral dorsal funiculus (short arrows), but many labeled axons arborize within the ipsilateral dorsal horn (long arrows). The density of these aberrant ipsilateral axons is particularly high adjacent to the dorsal funiculus (between the arrowheads). Scale bar, $100 \mu \mathrm{m}$.

behavioral task, the bilateral tactile-stimulation test, neonatally lesioned rats show a sensorimotor asymmetry. Although this asymmetry appears comparable to that observed in the adultoperated rats, previous work suggests that there may be differences. For example, Schallert and Whishaw (1985) found that rats receiving neonatal hemidecortications continue to show an asymmetry for up to 9 months after the lesion, whereas adultoperated rats recover within 3 months. Therefore, it is important to realize that the age-related effect described in the present study may be specific to certain forelimb-placing tasks.

Our observations implicate the SMC in the intact hemisphere in the recovery of placing reactions contralateral to neonatal cortical damage. How the intact cortex mediates this behavioral recovery needs to be clarified, but among the possibilities are the aberrant projections that have been shown to arise from the cortex remaining after unilateral neonatal cortical damage in rats (Hicks and D'Amato, 1970; Leong and Lund, 1973; Castro, 1975; Leong, 1976; Mihailoff and Castro, 1981; Castro and Mihailoff, 1983; Kartje-Tillotson and O'Donoghue, 1987; Naus et al., 1986). Our experiments certainly do not allow us to distinguish the involvement of one of these aberrant projections from the involvement of another. Indeed, our observations do not directly implicate any of these aberrant projections in the recovery of function.
Nonetheless, as a working hypothesis, the best candidate pathway to provide an anatomical basis for the behavioral recovery is the aberrant ipsilateral corticospinal projection, as this projection is, in effect, an ipsilateral homolog for the pathway thought normally to mediate at least some aspects of forelimb placing. The evidence linking the corticospinal projection with forelimbplacing behavior comes both from developmental observations and from lesion studies. The appearance and elaboration of the corticospinal pathway in the spinal cords of developing rats has been correlated temporally with the emergence and maturation of placing reactions (Hicks and D'Amato, 1975; Donatelle, 1977). Further, unilateral pyramidal tract transections cause rats and hamsters to misplace their contralateral forelimbs during locomotion (Barron, 1934; Reh and Kalil, 1982). The aberrant ipsilateral corticospinal projection from the remaining hemisphere after unilateral neonatal cortical damage essentially reestablishes the lost corticospinal projection. The cells of origin of the aberrant projection are in the appropriate layer, layer $\mathrm{V}$, and are generally found in the same region of the cortex as are the cells of origin of the normal crossed corticospinal projection (Huttenlocher and Raichelson, 1989; Reinoso and Castro, 1989). Furthermore, the distribution of the aberrant ipsilateral corticospinal axons within the spinal gray (Fig. 7) resembles that of the normal crossed corticospinal projection (Brown, 1971; An-
Figure 8. Photomicrographs from a horizontal section through the upper cervical spinal cord of a normal adult animal that received a unilateral lesion of the rostral cortex. $A$, Ipsilateral to the cortical lesion, normal fiber staining is apparent in the dorsal funiculus $(d f)$, and there is no evidence for degeneration in the spinal gray. $B$, Marked fiber degeneration is present in the contralateral dorsal funiculus $(d f)$ and fine, dustlike staining is found in the contralateral dorsal horn, especially adjacent to the dorsal funiculus. Scale bar, 50 $\mu \mathrm{m}$.
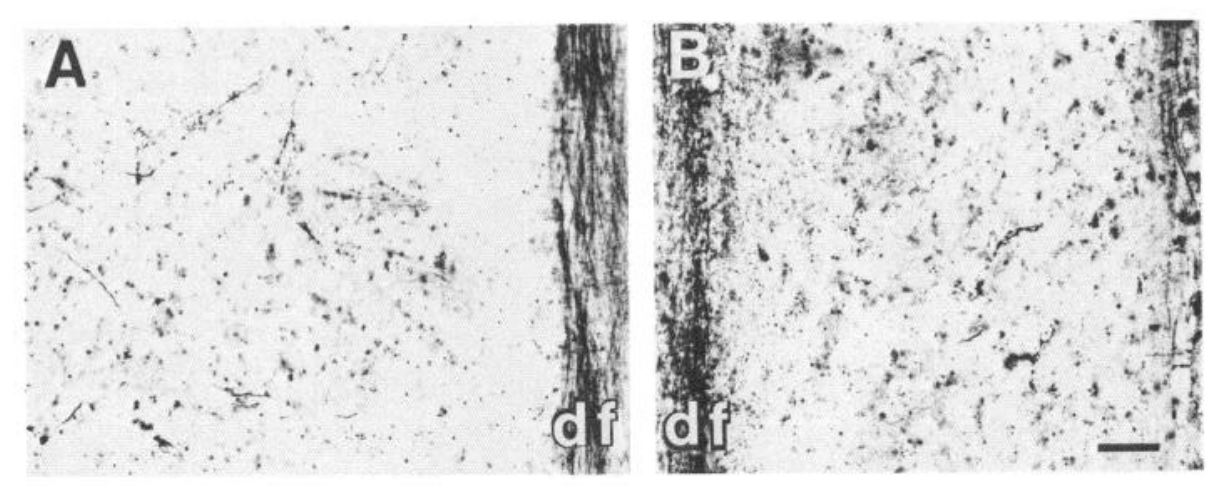


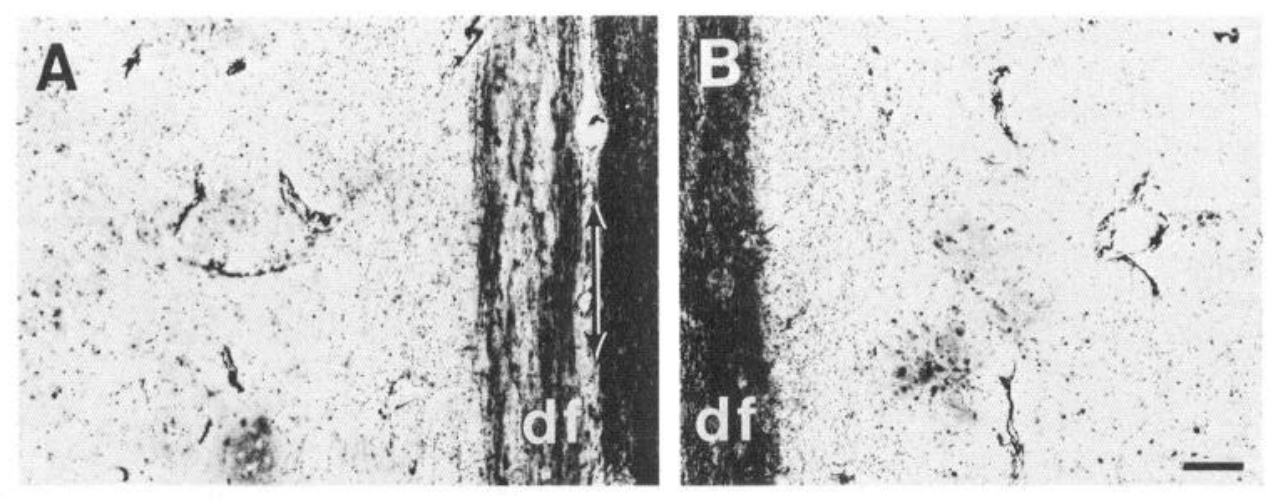

Figure 9. Photomicrographs from a horizontal section through the upper cervical spinal cord of an animal that received unilateral lesion of the rostral cortex at birth and second lesion of the contralateral cortex as an adult (NL/ $\mathrm{AL})$. A, The double-headed arrow marks the border between the dorsal funiculus $(d f)$ ipsilateral to the second lesion and the degenerating contralateral corticospinal tract. The ventral portion of the ipsilateral dorsal funiculus is shrunken and contains some degeneration particles, and silver-stain degeneration is abundant within the adjacent dorsal horn. $B$, Silver-stain-degeneration products are found in the dorsal funiculus $(d f)$, and in the spinal gray contralateral to the second lesion, as well. Scale bar, $50 \mu \mathrm{m}$.

tal, 1984; Gemma et al., 1987; Gribnau and Dederen, 1989). Thus, the aberrant ipsilateral corticospinal projection seems optimally poised to mediate the observed recovery of placing reactions following unilateral neonatal cortical damage.

Our anatomical observations not only confirm the presence of an aberrant ipsilateral corticospinal projection in those neonatally lesioned animals that were behaviorally tested, but also provide new information about the course of these aberrant fibers. Previous anatomical studies using silver-stain-degeneration techniques emphasized the deflection of the aberrant ipsilateral corticospinal fibers at the level of the pyramidal decussation (Hicks and D'Amato, 1970, 1975; Leong and Lund, 1973; Castro, 1975; Leong, 1976), and the presence of any intraspinal recrossing of corticospinal axons in these cases has even been explicitly denied (Leong, 1976). While our observations confirm the presence of aberrant corticospinal axons coursing in the ipsilateral dorsal funiculus, we have also noted that many, if not most, of the fluoro-ruby-labeled aberrant ipsilateral corticospinal axons in our material cross within the spinal cord at or near the segment in which they terminate (see Figs. 6, 7).

It has been suggested that the ipsilateral deflection of corticospinal fibers at the pyramidal decussation following neonatal cortical lesions in rats is a consequence of the absence in these animals of some normally occurring interaction in the lower medulla between the developing corticospinal bundles from the 2 sides (Leong and Lund, 1973). Consistent with this suggestion is the observation that an ipsilateral deflection of corticospinal fibers does not occur in cats with neonatal unilateral cortical lesions, presumably due to the precocious developmental state of the corticospinal projection at birth in this species, relative to that in rats (Gómez-Pinilla et al., 1986). Aberrant ipsilateral corticospinal fibers are seen in adult cats following neonatal cerebral hemispherectomy, but these fibers cross the midline within the spinal cord (Gómez-Pinilla et al., 1986) and follow a course similar to that described here for the aberrant ipsilateral corticospinal fibers that recross the midline within the spinal cord of rats. Thus, it would appear that, while the aberrant corticospinal fibers in rats with unilateral neonatal cortical lesions have access to the ipsilateral spinal cord through 2 routes, only 1 of these pathways is utilized in neonatally lesioned cats. If this difference reflects the maturational state of the corticospinal system in the 2 species, one might predict that cortical lesions performed somewhat later in rats would result in aberrant ipsilateral corticospinal axons crossing the midline only within the spinal cord in this species, as well.

In view of the large number of developmentally transient cortical projections described to date (e.g., Innocenti et al., 1977; Stanfield and O'Leary, 1985; Stanfield et al., 1982, 1987), it is easy to imagine that the aberrant ipsilateral corticospinal projection seen after unilateral neonatal cortical damage might not arise de novo, but rather, might be the result of the maintenance and elaboration of a normally transient projection. This seems
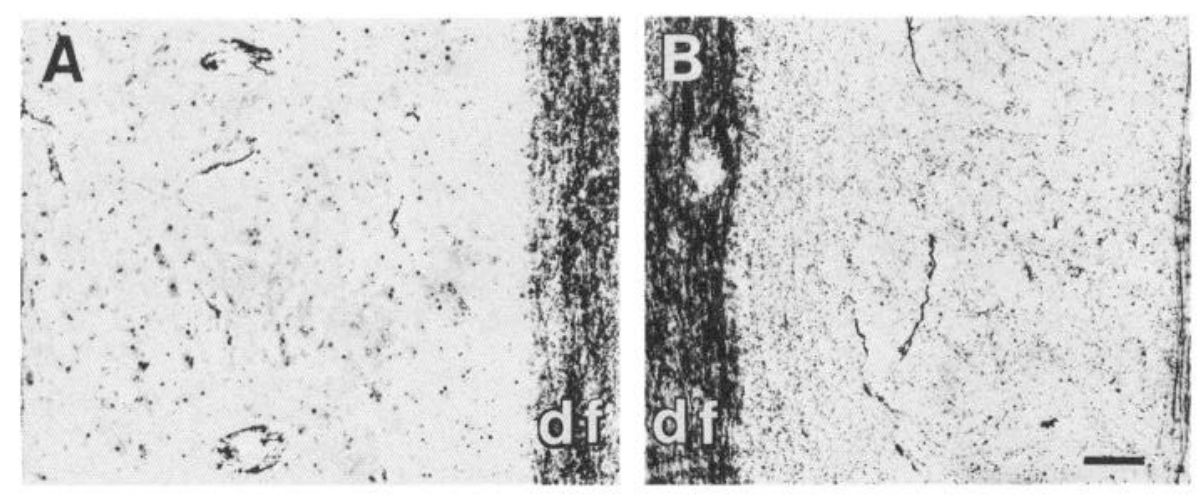

Figure 10. Photomicrographs from a horizontal section through the upper cervical spinal cord of an animal that received a unilateral lesion of the rostral cortex as an adult and a second lesion of the remaining cortex over 7 weeks later (AL/AL). $A$, Coarse fiber degeneration from the initial cortical lesion is still apparent within the dorsal funiculus $(d f)$ ipsilateral to the second lesion, but no fine, dustlike silver-staindegeneration products are seen in the adjacent dorsal horn. $B$, Contralateral to the second lesion, fiber degeneration is found within the dorsal funiculus $(d f)$ and silver-stain degeneration is abundant within the adjacent dorsal horn. Scale bar $50 \mu \mathrm{m}$. 
unlikely for those aberrant ipsilateral fibers deflected at the pyramidal decussation, especially as none of the anatomical studies of the development of the normal corticospinal projection in rats has presented evidence for a significant ipsilateral component (Nah et al., 1980; Jones et al., 1982; Schreyer and Jones, 1982; Joosten et al., 1987). However, fibers that recross the midline within the spinal cord have been described in kittens (Theriault and Tatton, 1989), and following neonatal cortical damage, these may develop into the aberrant ipsilateral corticospinal projection observed by Gómez-Pinilla et al. (1986). Before a similar role for such a transient projection in rats can be ruled out, the formation of the aberrant ipsilateral corticospinal projection needs to be examined directly.

Although we have emphasized the involvement of the intact SMC in recovery following unilateral neonatal lesions, it is likely that there are several additional mechanisms of recovery in neonate- and adult-lesioned animals. For example, both the ipsilateral and contralateral components of the placing deficit, observed after the second lesion in the NL/AL rats, eventually showed some signs of recovery. This suggests that, though the intact SMC may be involved in the recovery following a unilateral neonatal lesion, the recovery following the second lesion (as an adult) involves a different process. Previous work indicates that experience with the task may be an important factor in the recovery of limb placing in adult-lesioned animals (Feeney et al., 1982). Thus, the recovery following the adult lesion may reflect the establishment of an alternate behavioral strategy in order to successfully perform the task (Finger and Stein, 1982; Finger and Almli, 1985; Hernandez and Schallert, 1988; Barth et al., 1990a). This idea may also help explain the results of the AL/AL group, because in those animals, the remaining hemisphere does not seem to be involved in the behavioral recovery (the second lesion produced behavioral deficits only contralateral to the second lesion), and an aberrant ipsilateral corticospinal projection does not occur following unilateral cortical damage in adults. Finally, the recovery from sensorimotor asymmetry as measured by the bilateral tactilcstimulation test may involve yet another process in neonataland adult-lesioned animals. Recent studies in adult-lesioned animals have shown that drugs affecting the rate of recovery from somatosensory asymmetry do not have a similar effect on recovery of forelimb-placing behavior (Hernandez and Schallert, 1988; Barth et al., 1990a). It has been suggested that recovery from somatosensory asymmetry may involve the reactivation of subcortical structures distant from the lesion site (Schallert et al., 1986).

In summary, it seems apparent that there are different mechanisms that provide for the recovery that follows unilateral SMC lesions in neonates and adult rats. In rats receiving a lesion as a neonate, the intact SMC appears to be involved in some aspects of recovery of forelimb-placing reactions. Moreover, the neural substrate mediating the recovery may be an aberrant ipsilateral pathway. In contrast, in rats lcsioncd as adults, there is no evidence to suggest that the intact SMC is involved in recovery.

\section{References}

Antal M (1984) Termination areas of corticobulbar and corticospinal fibres in the rat. J Hirnforsch 25:647-659.

Barron DH (1934) The results of unilateral pyramidal tract section in the rat. J Comp Neurol 60:45-55.
Barth TM, Schallert T (1987) The role of the superior colliculus, somatosensory cortex and lateral hypothalamus in somatosensory function in the rat. Exp Neurol 95:661-678.

Barth TM, Jones TA, Schallert T (1987) Recovery of function after unilateral cortical lesions: contribution of the contralateral cortex. Soc Neurosci Abstr 13:1234.

Barth TM, Grant ML, Schallert T (1990a) Effects of MK-801 on recovery from sensorimotor cortex lesions. In: Stroke, in press.

Barth TM, Jones TA, Schallert T (1990b) Functional subdivisions of the rat somatic sensorimotor cortex. Behav Brain Res 39:73-95.

Broca $P$ (1865) Siège do la faculté do langage articulé dans l'hemisphere gauche do cerveau. Bull Soc Anthropol 6:377-393.

Brooks CM (1933) Studies on the cerebral cortex. II. Localized representation of hopping and placing reactions in the rat. Am J Physiol 105:162-171.

Brown LT (1971) Projections and termination of the corticospinal tract in rodents. Exp Brain Res 13:432-450.

Brown TG (1915) On the activities of the central nervous system of the unborn foetus of the cat; with a discussion of the question whether progression (walking, etc.) is a "learnt" complex. J Physiol (Lond) 49:208-215.

Castro AJ (1975) Ipsilateral corticospinal projections after large lesions of the cerebral hemisphere in neonatal rats. Exp Neurol 46:1-8.

Castro AJ, Mihailoff GA (1983) Corticopontine remodeling after cortical and/or cerebellar lesions in newborn rats. J Comp Neurol 219: 112-123.

de Castro JM, Zrull MC (1988) Recovery of sensorimotor function after frontal cortex damage in rats: evidence that the serial lesion effect is due to serial recovery. Behav Neurosci 102:843-851.

De Ryck M, Van Rempts J, Borgers M, Wauquier A, Janssen PAJ (1989) Photochemical stroke model: flunarizine prevents sensorimotor deficits after neocortical infarcts in rats. Stroke 20:1383-1390.

Donatelle JM (1977) Growth of the corticospinal tract and the development of placing reactions in the postnatal rat. J Comp Neurol 175:207-232.

Faugier-Grimaud S, Frenois C, Stein DG (1978) Effects of posterior parietal lesions on visually guided behavior in monkeys. Neuropsychologia 16:151-168.

Feeney DM, Gonzalez A, Law WA (1982) Amphetamine, haloperidol, and experience interact to affect rate of recovery after motor cortex injury. Science 217:855-857.

Finger S, Almli R (1985) Brain damage and neuroplasticity: mechanisms of recovery or development? Brain Res Rev 10:177-186.

Finger S, Stein DG (1982) Brain damage and recovery: research and clinical perspectives. New York: Academic.

Freud S (1897) Die cereballahmung. Vienna: A. Holder.

Gemma M, Perego GB, Pizzini G, Tredici G (1987) Distribution of the corticospinal fibers in the cervical and lumbar enlargements of the rat spinal cord. J Hirnforsch 28:457-462.

Gómez-Pinilla F, Villablanca JR, Sonnier B-J, Levine MS (1986) Reorganization of pericruciate cortical projections to the spinal cord and dorsal column nuclei after neonatal or adult cerebral hemispherectomy in cats. Brain Res 385:343-355.

Gribnau AAM, Dederen PJWC (1989) Collateralization of the cervical corticospinal tract in the rat. Neurosci Lett 105:47-51.

Hernandez TD, Schallert T (1988) Seizures and recovery from experimental brain damage. Exp Neurol 102:318-324.

Hicks SP, D'Amato CJ (1970) Motor-sensory and visual behavior after hemispherectomy in newborn and mature rats. Exp Neurol 29: 416-438.

Hicks SP, D'Amato CJ (1975) Motor-sensory cortex-corticospinal systcm and developing locomotion and placing in rats. Am J Anat 143:1-34.

Huttenlocher PR, Raichelson RM (1989) Effects of neonatal hemispherectomy on location and number of corticospinal neurons in the rat. Dev Brain Res 47:59-69.

Innocenti GM, Fiore L, Caminiti R (1977) Exuberant projection into the corpus callosum from the visual cortex of newborn cats. Neurosci Lett 4:237-242.

Jones EG, Schreyer DJ, Wise SP (1982) Growth and maturation of the rat corticospinal tract. Prog Brain Res 57:361-379. 
Joosten EAJ, Gribnau AAM, Dederen PJWC (1987) An anterograde study of the developing corticospinal tract in the rat: three components. Dev Brain Res 36:121-130.

Kalaha-Brunst C, Giolli RA, Creel DJ (1974) An improved silver impregnation method for tracing degenerating nerve fibers and their terminals in frozen sections. Brain Res 82:279-283.

Kartje-Tillotson G, Neafsey EJ, Castro AJ (1985) Electrophysiological analysis of motor cortical plasticity after cortical lesions to newborn rats. Brain Res 332:103-111.

Kartje-Tillotson G, O'Donoghue DL (1986) Topography of corticopontine remodelling after cortical lesions in newborn rats. J Comp Neurol 250:206-214.

Kartje-Tillotson G, Neafsey EJ, Dauzvardis MF, Castro AJ (1987) Pyramidotomy abolishes the abnormal movements evoked by intracortical microstimulation in adult rats that sustained neonatal cortical lesions. Brain Res 415:172-177.

Kennard MA (1936) Age and other factors in motor recovery from precentral lesions in monkeys. Am J Physiol 115:138-146.

Kennard MA (1938) Reorganization of motor function in the cerebral cortex of monkeys deprived of motor and premotor areas in infancy. J Neurophysiol 1:477-496.

Kennard MA, Ectors L (1938) Forced circling in monkeys following lesions of the frontal lobes. J Neurophysiol 1:45-54.

Kolb B, Gibb R (1987) Dendritic proliferation as a mechanism of recovery and sparing of function. Soc Neurosci Abstr 13:1430.

Kolb B, Holmes C (1983) Neonatal motor cortex lesions in the rat: absence of sparing of motor behaviors and impaired spatial learning concurrent with abnormal cerebral morphogenesis. Behav Neurosci 97:697-709.

Kolb B, Tomie J (1988) Recovery from early cortical damage in rats. IV. Effects of hemidecortication at 1,5 or 10 days of age on cerebral anatomy and behavior. Behav Brain Res 28:259-274.

Kolb B, Whishaw IQ (1985) Earlier is not always better: behavioral dysfunction and abnormal cerebral morphogenesis following neonatal cortical lesions in the rat. Behav Brain Res 17:25-43.

Kolb B, Whishaw IQ (1989) Plasticity in the neocortex: mechanisms underlying recovery from early brain damage. Prog Neurobiol 32: 235-276.

Kolb B, Sutherland RI, Whishaw IQ (1983) Neonatal hemidecortication or frontal cortex ablation produces similar behavioral sparing but opposite effects on morphogenesis of remaining cortex. Behav Neurosci 97:154-158.

Langworthy OR (1924) A physiological study of the reactions of young decerebrate animals. J Physiol (Lond) 69:254-264.

Langworthy OR (1926) Relation of onset of decerebrate rigidity to the time of myelination of tracts in the brain-stem and spinal cord of young animals. Contrib Endocrinol 17:127-140.

Leong SK (1976) An experimental study of the corticofugal system following cerebral lesions in the albino rat. Exp Brain Res 26:235247.

Leong SK, Lund R (1973) Anomalous bilateral corticofugal pathways in albino rats after neonatal lesions. Brain Res 62:218-221.

Mihailoff GA, Castro AJ (1981) Autoradiographic and electron microscopic degeneration evidence for axonal sprouting in the rat corticopontine system. Neurosci Lett 21:267-273.

Nah SH, Ong LS, Leong SK (1980) Is sprouting the result of a persistent neonatal connection? Neurosci Lett 19:39-44.
Naus CC, Flumerfelt BA, Hrycyshyn AW (1986) Contralateral corticorubral fibers induced by neonatal lesions are not collateral of the normal ipsilateral projection. Neurosci Lett 70:52-58.

Norsell U (1967) A conditioned reflex study of sensory defects caused by cortical somatosensory ablations. Physiol Behav 60:327-353.

Reh T, Kalil K (1982) Functional role of regrowing pyramidal tract fibers. J Comp Neurol 211:276-283.

Reinoso BS, Castro AJ (1989) A study of corticospinal remodelling using retrograde fluorescent tracers in rats. Exp Brain Res 74:387394.

Schallert T, Whishaw IQ (1984) Bilateral cutaneous stimulation of the somatosensory system in hemidecorticate rats. Behav Neurosci 98: 518-540.

Schallert T, Whishaw IQ (1985) Neonatal hemidecortication and bilateral cutaneous stimulation in rats. Dev Psychobiol 18:501-514.

Schallert T, Upchurch M, Lobaugh N, Farrar SB, Spirduso WW, Gilliam P, Vaughn D, Wilcox RE (1982) Tactile extinction: distinguishing between sensorimotor and motor asymmetries in rats with unilateral nigrostriatal damage. Pharm Biochem Behav 16:455-462.

Schallert T, Hernandez TD, Barth TM (1986) Recovery of function after brain damage: severe and chronic disruption by diazepam. Brain Res 379:104-111.

Schmued LC, Heimer L (1989) Circuitry of the extended amygdala: introducing the use of fluorescent dextrans for rapid, anterograde and retrograde tract tracing. Soc Neurosci Abstr 15:306.

Schmued LC, Kyriakidis K, Heimer L (1990) In vivo anterograde and retrograde axonal transport of the fluorescent rhodamine dextran amine, fluoro-ruby, within the CNS. Brain Res, in press.

Schreyer DJ, Jones EG (1982) Growth and target finding by axons of the corticospinal tract in prenatal and postnatal rats. Neuroscience 7: 1837-1853.

Sharp FR, Gonzalez MF (1986) Adult rat motor cortex connections to thalamus following neonatal and juvenile frontal cortical lesions: WGA-HRP and amino acid studies. Dev Brain Res 30:169-187.

Soltmann $O$ (1876) Experimentalle studien über die functionen des grosshirns der neugeborenen. J Kinderheil 9:106-148.

Stanfield BB, O'Leary DDM (1985) The transient corticospinal projection from the occipital cortex during the postnatal development of the rat. J Comp Neurol 238:236-248.

Stanfield BB, O'Leary DDM, Fricks C (1982) Selective collateral elimination in early postnatal development restricts cortical distribution of rat pyramidal tract neurones. Nature 298:371-373.

Stanfield BB, Nahin BR, O'Leary DDM (1987) A transient postmamillary component of the rat fornix during development: implications for intcrspecific differences in mature axonal projections. J Neurosci 7:3350-3361.

Theriault E, Tatton WG (1989) Postnatal redistribution of pericruciate motor cortical projections within the kitten spinal cord. Dev Brain Res 45:219-237.

Vulpian A (1866) Leçons dur la physiologie générale et comparée du système nerveaux. Paris: Balliére.

Weed LH (1917) The reactions of kittens after decortication. Am J Physiol 43:131-157.

Whishaw IQ, Kolb B (1988) Sparing of skilled forelimb reaching and corticospinal projections after neonatal motor cortex removal or hemidecortication in the rat: support for the Kennard doctrine. Brain Res 451:97-114. 